\title{
ERRATUM
}

Steven B. Kraines · Masahiko Isobe - Hiroshi Komiyama

\section{Seasonal variations in the exchange of water and water-borne particles at Majuro Atoll, the Republic of the Marshall Islands}

Published online: 19 February 2002

(C) Springer-Verlag 2002

\section{Coral Reefs (2001) 20:330-340}

In Fig. 1 of Kraines et al. (2001), the upward pointing triangle shows the location of the Majuro Weather Station. The downward pointing triangles and the open square show the locations of survey stations from previous survey work described in Kraines et al. (1999) The corrected figure corresponding to the figure citation in Kraines et al. (2001) is given in this erratum (Fig. 1).

\section{References}

Kraines SB, Isobe M, Komiyama H (2001) Seasonal variations in the exchange of water and water-borne particles at Majuro Atoll, the Republic of the Marshall Islands, Coral Reefs 20:330-340

Kraines SB, Suzuki A, Yanagi T, Isobe M, Guo X, Komiyama H (1999) Rapid water exchange between the lagoon and the open ocean at Majuro Atoll due to wind, waves, and tide. J Geophys Res 104:15635-15653

Fig. 1.

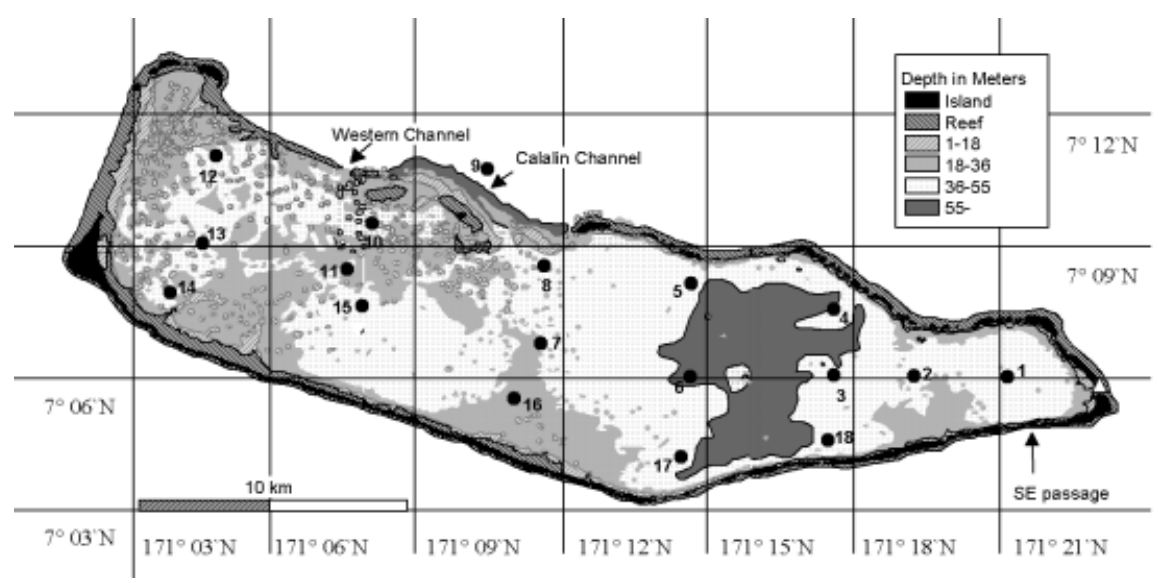

The online version of the original article can be found at http:// dx.doi.org/10.1007/s00338-001-0191-8.

S.B. Kraines $(\bowtie) \cdot$ H. Komiyama

Department of Chemical Systems Engineering,

The University of Tokyo, 7-3-1 Hongo, Bunkyo-ku,

Tokyo 113, Japan

E-mail: steven@prosys.t.u-tokyo.ac.jp

Tel.: + 81-3-38122111 ext. 7318

Fax: $+81-3-56897352$

M. Isobe

Institute of Environmental Studies,

The University of Tokyo, 7-3-1 Hongo, Bunkyo-ku,

Tokyo 113, Japan 